\section{Anita Nudelman}

Ben Gurion University, Israel

\section{Santiago Boira}

University of Zaragoza, Spain

\section{Tina (Tiko) Tsomaia}

Georgian Institute of Public Affairs (GIPA), Georgia

\section{Ecaterina Balica}

Romanian Academy, Romania

\section{Sopio Tabagua}

The Georgian Centre for Psychosocial and

Medical Rehabilitation of Torture Victims (GCRT),

Georgia

\section{"Hearing Their Voices": Exploring Femicide among Migrants and Culture Minorities}

DOI: https://doi.org/10.18778/1733-8077.13.3.04

Abstract

rates of domestic violence and femicide in various European countries tend to be higher among migrant women, as well as among women from cultural minorities. This led to the development of a culture and gender-sensitive in-depth interview guide aimed at better understanding this phenomenon, as well as identifying specific aspects of the experience of violence in a foreign scenario. The first stage was developing a draft interview guide based on the most important issues addressed in the professional literature, relating both to victims of domestic violence and to survivors of femicide and their families. This has allowed others to "hear their voices" and to understand their own perspectives, which are especially important considering the steady increase of this phenomenon around the world. The second phase was a pilot study among immigrant femicide survivors: first in Spain, later in Romania, and finally in Georgia, focusing on internally displaced people. The last step was analyzing the feedback from the different countries, which led to a refined and improved version of the interview guide. Thus, the current paper presents an ongoing process leading to a standardized interview guide, which could be adapted to local socio-cultural contexts, enabling comparative studies across Europe.

Keywords
Anita Nudelman is an applied medical anthropologist who lectures in the Faculty of Health Sciences and the African Studies Program at Ben Gurion University (Israel). Her areas of expertise include gender issues, sexual health, and HIV. She has led UNAIDS sponsored community-based Rapid Assessment Processes in Africa, as well as projects related to culture and gender transformative sexual health (including prevention of gender-based violence) and HIV prevention. She is active in the COST Action IS1206 "Femicide across Europe" and Co-Chair of the Committee on Anthropology and HIV/AIDS, International Union of Anthropological and Ethnological Studies (IUAES). email address: anitanudelman@hotmail.com

Santiago Boira graduated in Psychology from the University of Salamanca (Spain) and received his PhD from the University of Zaragoza (Spain). He is currently a Lecturer in the Department of Psychology and Sociology and coordinator of the Master's degree in Gender Relations at the University of Zaragoza. His research interests focus on gender issues, intimate partner violence, especially in male abusers. He is a member of the network "Femicide across Europe," Cost Action IS1206. He is a researcher of the Group of Social and Economic Studies of the Third Sector (GESES).

email address: sboira@unizar.es

Tina (Tiko) Tsomaia is a Professor at the Caucasus School of Journalism and Media Management (CSJMM) of the Georgian Institute of Public Affairs (GIPA), where she is completing her $\mathrm{PhD}$ in Social Sciences. She has a BA and MA in Medicine and an MA in Journalism and Media Management. She was a post-graduate research fellow at the Arthur L. Carter Journalism Institute, New York University. She is an MC member of the COST Action IS1206 "Femicide across Europe" and a board member of the Georgian Psychotrauma Society Her research topics are: pre-natal sex selection, trauma and addiction, ethical decision-making, and health communication.

email address: tsomaiat@gmail.com

Ecaterina Balica is a senior researcher at the Institute of Sociology of the Romanian Academy. She is a member of the Scientific Committee of the Romanian Society of Criminology (2013 to present) and of the "Association Internationale des Criminologues de Langue Française" (AICLF). She is a Romanian representative in the Management Committee of COST Action IS1206 "Femicide across Europe." In the past years, her research has focused on homicide-suicides, femicide-suicides, migration and crime, and restorative justice. The results of her studies were published in international peer reviewed journals, in book chapters, and international conferences.

email address: catibalica@yahoo.com

Sopio Tabaghua graduated from Tbilisi State Medical University in 2002. She is a licensed psychiatrist-psychotherapist. Since 2003, she has been practicing in the field of rehabilitation. Currently she is a coordinator at The Georgian Centre for Psychosocial and Medical Rehabilitation of Torture Victims (GCRT) and psychiatrist in the Mental Health Hospital. She is preparing for the entrance examinations for a doctoral degree; her interest is "Endophenotypic characteristics of schizophrenia." She is a board member of Human Rights House Tbilisi, which runs the free legal aid center for socially unprotected people in Georgia and a member of the Georgian Society of Psychotrauma.

email address: sopotaba@gmail.com 
Background

While attending a meeting in the context of COST (European Cooperation in Science and Technology) Action IS1206, dedicated to "Femicide across Europe" in 2014 (Weil 2015), the participants were asked to prepare country presentations on the cultural aspects of femicide. Subsequently, the first two authors discussed this issue in their respective countries. In Israel, the data indicated that most femicide victims belonged to immigrant communities (Israeli Parliament 2015), such as Ethiopian and the ex-Soviet Republics (Sela-Shayovitz 2010; Edelstein 2013), to culture minorities, such as Israeli Arab citizens (Shalhoub-Kevorkian 2003; Abu Rabia 2011), and to asylum seekers. ${ }^{1}$

In addition, the Instituto de la Mujer (Women's Institute) of the Government of Spain reported that in $2015,36.7 \%$ of murdered women were foreigners. ${ }^{2}$ During the discussions in the aforesaid COST meeting, other group members confirmed that this trend was similar across countries.

Literature Review

Various studies have indicated that migrant women are highly vulnerable to domestic violence in host countries. This is due to legal, language, and cultural barriers which lead to isolation, and is compounded by their low socio-economic status, influencing their possibilities to lodge complaints,

${ }^{1}$ As unofficially reported by the Center for Eritrean Women in Tel Aviv. See: http://the-migrant.co.il/en/node/49. 2 Instituto de la Mujer y para la Igualdad de Oportunidades
del Gobierno de España. Retrieved July 01, 2015 (http://www. inmujer.gob.es/estadisticas/consulta.do?metodo=buscar). as well as their access to support networks and assistance (Ingram 2007; Runner, Yoshihama, and Novick 2009; Rana 2012). In a recent survey done by the European Union Agency for Fundamental Rights (2014), a higher prevalence rate of physical and/or sexual violence was found among women who are not citizens of their country of residence. In fact, domestic violence is a significant form of victimization of female immigrants (Davis, Erez, and Avitabile 2001; Raj and Silverman 2002; $\mathrm{Ha}-$ zen and Soriano 2007; Gracia et al. 2010; Carbajosa et al. 2011).

Considering Spain, out of the 123,725 complaints filed on domestic violence in 2015, 30.1\% included a non-Spanish victim (Consejo General del Poder Judicial 2015). In addition, the data of the macro survey on violence against women in 2015 indicate that $59.7 \%$ of women over 16 years who admitted having suffered physical or sexual violence from their partner, former partner, or any partner in the past 12 months were foreigners (Ministerio de Sanidad, Servicios Sociales e Igualdad 2015). According to official data from the Ministry of Sanitation, Social Services, and Equality of Spain, 22 of the 60 women killed due to domestic violence in Spain in 2015 were foreigners. This percentage has increased throughout the years, from $14.3 \%$ in 2000 to $36.7 \%$ in 2015 . In addition, $26.7 \%$ of the aggressors (men) in 2015 were foreigners (Instituto de la Mujer y para la Igualdad de Oportunidades n.d.). During 2010-2011, 135 women were killed by their partners and 39.7\% were foreigners (Africa-Asia 11.5\%, the rest of Europe 10.7\%, and America-North and South 17.6\%). The countries from which the highest number of victims origi- nated were Ecuador and Morocco (Sanz-Barbero et al. 2016).

In Romania, a study drew attention to the emigrant $^{3}$ women's vulnerability including types of violence and femicide acts (Balica and Stöckl 2016). It emphasized that approximately $30 \%$ of the homicide-suicide cases identified in Romania for the period 2002-2013 were committed between Romanian emigrants/former emigrants (Balica and Stöckl 2016), and most of them were intimate partner femicide-suicides ${ }^{4}(84 \%)$. A comparative analysis between the intimate partner femicides and intimate partner femicide-suicides emphasized the fact that the emigrant status (of the victim, of the aggressor, or of both) increases the risk of escalating from violent acts in intimate partner relationships to femicide or femicide-suicide (Balica 2016). It was found that the association of jealousy with suspicion of infidelity and other issues (domestic violence, financial problems, alcohol consumption, depression) were among the factors determining intimate partner femicides or intimate partner femicide-suicides between Romanian emigrants. Both of the studies mentioned were not based on direct interviews with femicide survivors, but on the analysis of information from interviews with aggressors and other sources (such as penal files).

According to a reproductive health survey in Georgia, $6.2 \%$ of married women (or those that had been married before) reported intimate part-

${ }^{3}$ Romanian women that had immigrated to other countries and later returned to Romania.

${ }^{4}$ Among the different forms of femicide, it can be followed by the aggressor's suicide (Laurent, Platzer, and Idomir 2013). ner violence (IPV), being more widespread among ethnic minorities (Georgians-5.3\%, Azeri-11.2\% Armenians-7.9\%, and other ethnicities-12.6\%). In addition, only one out of every three victims of violence sought medical or legal help, the main reasons being embarrassment, not doing any good, and bringing a bad name to family (Ross 2012).

In addition, the data provided by the Prosecutor's Office of Georgia show that in 2014-2015, 53 women were killed. Twenty seven of all murders were so called "domestic killings," 18 women were killed by their intimate partners, while in the rest of cases femicide was performed by other family members (such as the father-in-law or the victim's brother). According to the same analysis, out of the 27 femicide cases, the majority of victims were ethnic Georgians: one was Ukrainian, three were Azerbaijanis, one Armenian, and one Russian (Prosecutor's Office of Georgia 2015).

Official statistics over the years show that domestic violence and femicide are increasing in Georgia. This could be influenced partly by better access to statistics on femicide, but mainly due to conditions of economic hardship, as well as to the history of armed conflicts Georgia experienced in the 1990s and in 2008 in the regions of Abkhazia and South Ossetia, which resulted in displacement of approximately 428,000 people, of whom 232,700 remain as internally displaced persons (IDPs), according to IDMC estimates (IDMC 2014).

The majority of IDPs currently live in government-established IDP collective settlements, characterized by poor living conditions, high unemployment, 
poverty, and low access to healthcare (WHO 2009). These tend to increase tensions among families and couples, including domestic violence and femicide. In addition, IDPs exposure to conflict-related violence, forced displacement, and loss of loved ones, homes, and livelihoods has been associated with prolonged poor mental health (Makhashvili et al. 2014). Thus, the risk of femicide is increased, considering that many perpetrators have mental health problems and that their access to mental health services is limited (Chikovani et al. 2015).

The vulnerabilities of immigrants and especially women, such as increased violence and abuse, are well documented in professional literature. Nevertheless, it was important to obtain a deeper understanding of women's risks (Nicolaidis et al. 2003; Herrera 2013; Messing et al. 2013), as well as of the circumstances preceding the femicide and of the triggers that led men to actually kill women, usually their wives or partners (Boira and Marcuello 2013).

Even though the victims are not here to tell their stories, it is possible to obtain them from kin, neighbors, and friends, as well as from failed femicide attempts (Weil 2016). For this purpose, a few researchers had already embarked in qualitative research, interviewing family members and close friends of the victims, such as McNamara (2008) in Australia and Sheehan and colleagues (2015) in the United States, although they did not target immigrants. Gonzalez-Mendez and Santana-Hernandez (2012) and Briones-Vozmediano and colleagues (2014) interviewed professionals in Spain, who had been involved with femicide victims. The first qualitative investigation based on in-depth interviews of femicide survivors was the pioneer study initiated by a working group including Nicolaidis and colleagues (2003) in the U.S., which targeted mostly European Americans and African Americans, while important minorities, including Latinos, were not represented. Thus, it was decided to pursue this direction in order to obtain an insider's perspective from survivors of femicide attempts in Europe-either immigrants, IDPs, or those belonging to cultural minorities.

The review of the situation in the three countries that participated in the pilot study: Spain, Romania, and Georgia, shows some elements that may be crucial when considering violence against women, which due to different circumstances are living outside of their own country, area of origin, and/or in a different cultural contexts.

This article presents an ongoing project to develop in-depth culture and a gender-sensitive interview guide to explore femicide of immigrant women and to identify specific aspects of the experience of violence in a foreign scenario. This method enables us to "hear their voices" and understand survivors' perspectives and their personal experiences regarding this increasing global phenomenon. This paper focuses mostly on the usefulness of this methodology, and not on the detailed content analysis of the data.

\section{Methodology}

It was decided to develop a qualitative in-depth interview tool, considering the main risk factors of immigrant/displaced women or women from cultural minorities, as well as their personal experiences as survivors of attempted femicide. The guide was designed to be flexible enough to allow for culture adaptation, considering the various countries of origin, the immigration processes, and the specific contexts in the host countries in Europe. Cultural and gender codes and the background in their country of origin (such as rural or urban) were also given special consideration, since all these may strongly influence how to approach and support survivors of attempted femicide in a culture and gender sensitive way.

Based on the Danger Assessment (DA) instrument, Campbell and colleagues in the U.S. developed a culture-competent intimate partner violence risk assessment tool for immigrant women (DA-I) to identify victims who are at risk of lethal violence from an intimate (or ex-intimate) partner (Messing et al. 2013). In their 2003 study, the group headed by Campbell had used an in-depth interview guide, which they discussed with us (personal communication with Nicolaidis and Campbell).

\section{The Interview Guide}

The interview guide was developed by the first two authors (Nudelman and Boira), going through various phases of revision, including discussions with social workers, psychologists, and lawyers dealing daily with victims of partner violence and femicide survivors. The initial tool was based on their combined research experiences: Santiago Boira has worked both in Women
Social Services and with femicide perpetrators in prisons in Spain (e.g., Boira 2010; Boira and Jodrá 2010; Boira et al. 2013), while Anita Nudelman has worked with Ethiopian immigrants in Israel. She has lead UNAIDS sponsored qualitative Rapid Assessment Process studies in Africa, examining the gender and culture barriers to utilization of maternal and HIV services-among them the fear of abandonment, violence, and being killed by their partners-often related to the disclosure of a woman's HIV status (Nudelman 2013).

The interview guide is divided into five sections (with some specific items to be included according to each attempted femicide survivor being interviewed and to her own "story"): life in the country/place of origin, the immigration process, life in the host country, the event (attempted femicide), and the rehabilitation process.

1. Life in the country of origin or before forced displacement: growing up, family life, education, jobs, et cetera. If her relationship with her violent partner began in the country of origin, an additional probing is included (development of relationship, changes, problems, coping, support networks, etc.).

2. The immigration/displacement process: reasons that led to migration, family support, the overall experience since leaving the home country until arrival in the host country, IDP camp, et cetera.

3. Life in the host country. The first period after arrival, her social support networks, the 
relationship with her violent partner (with different options, depending on whether the violent partner was the same person as in the country of origin or if he is a new partner whom she met in the host country). It investigates their relationship, the problems and changes that occurred, and their causes (such as economic factors, control issues, jealousy, substance abuse), as well as violent episodes and the woman's response/behavior and search for assistance. A special part is dedicated to the victim's relationship with a citizen of the host country and how her immigrant/displacement status (often illegal) affects both the relationship and the use of official support services (and specifically the barriers to seek assistance from police, health and social services).

4. The event (attempted femicide, which is often a turning point in the life of the victim). This section deals with the violent episode that often led to hospitalization and/or to an official police complaint of the partner by the victim. It is the heart of the interview process, including the signs and events preceding the femicide attempt, the attempt itself, how the woman was saved and helped in real time, and how the perpetrator was punished. It includes a reflection process in which the survivor is asked to look back for warning signs and think if she could have done something to prevent this event. The risk of immigrant women is also assessed compared to local ones.

5. Rehabilitation. This section covers the ongoing process from the incident to date. It address- es how the survivor overcame the event, who provided assistance to her (official services, women's organizations, family or friends support), including detailed positive and negative experiences related to the process. It dwells on how her immigration status affected her interaction with the police, health and social services, judicial system, et cetera. Finally, her life at present and her dreams and plans for the future are discussed.

6. The interview ends by asking the survivor what advice she would give other immigrant/ displaced women whose partners are violent.

\section{The Pilot Study}

Spain-and specifically Zaragoza-was chosen to be the first pilot country. It was appropriate for the joint venture, considering that Santiago Boira is a psychologist who lives and works in this city, and Anita Nudelman, a medical anthropologist, is also a native Spanish speaker.

The original interview guide (developed in English) was translated into Spanish and culturally adapted to the social and cultural context of immigrants in Zaragoza.

Official women's organizations and services were contacted and meetings were held to discuss the pilot project with professionals working with victims of domestic violence and femicide survivors. The draft (Spanish) interview guide was presented and feedback was received. The caseworkers identified immigrant women survivors of femicide, whom they considered would be able to speak about their experience. Those willing to participate received a detailed explanation of the aims of this study and of the interview process and gave their consent.

Additional countries were included in the second phase. As a visiting scholar in Rome, Italy, Ecaterina Balica, a sociologist, interviewed a Romanian emigrant survivor of femicide, translating the interview guide into Romanian. The participant was identified during exploratory research among the Romanian emigrant community, through information received from relatives, and not with the assistance of institutions for social services or victim protection as in the other countries participating in the project.

In Georgia, Tina (Tiko) Tsomaia, a journalist and lecturer, who is researching the phenomena of sex-selective abortions, translated the interview guide into Georgian. She contacted Sopio Tabagua, a psychiatrist and manager of the Georgian Center for Psychological and Medical Rehabilitation of Torture Victims. This organization has a branch in Gori, which works with the victims of violence, including IDPs. Social workers and psychologists identified survivors of femicide who had a history of displacement (12 women out of total 61 that used their services in the years of 2014-2016) and could speak about their experiences. The aims of the study were explained to them and after receiving informed consent from six women, meetings were scheduled in Gori Service Center, where they were interviewed by Tsomaia and Tabagua.

\section{The Participants}

The first pilot in Spain included 3 immigrant femicide survivors (2 from Latin America and one from Romania); aged 33 to 37, all of them had been in Spain for more than 10 years. The survivor from Romania had gone back and forth a few times and her relationship was with a man she had married at a young age in her home village. The two South American women were middle class with college level education and both married Spanish men: one in her country of origin and the second shortly after arriving in Spain. All the women had one child.

The second Romanian survivor had immigrated to Italy in 2000. She was a 38-year-old housewife with a high school education, married to a 65-year-old Italian man. They have an 11-year-old son (with health problems). At the time of the interview they were living together.

Six interviews were conducted in Georgia, five were IDPs and one was a refugee from Chechnya. Out of six interviewed women aged 27-50, five had IDP backgrounds: three of them were internally displaced from the South of Ossetia and two were displaced from Abkhazia. Five of the participants were ethnic Georgians, one Chechen; five were Christians and one was Muslim. All the women had children (1,2, or 3 each) from both genders. Half of them had secondary education and half higher education. At the time of the interviews, all participants but one had jobs. 


\section{The Interviews}

In Spain, the interviews were scheduled by the survivors' therapist or caseworker according to the survivors' convenience and took place inside of Women Protection Services (a familiar environment, where they have been helped and continue to meet their caseworkers). After obtaining consent from each participant, both researchers participated in the interview, although-for gender considerationsthey were mostly conducted by Anita Nudelman. They lasted between 1.30 to 2 hours each, were recorded and later transcribed by a professional transcriber. After each interview, notes were compared and summarized. The process was similar in Georgia, where both researchers jointly conducted the first interview and the following ones separately.

In the case of the Romanian immigrant in Italy, the interview was scheduled directly by the researcher, who already knew the participant who had been a victim of domestic violence. However, it was the survivor's mother who told her about the increased violence of her Italian husband, which culminated in the failed femicide. After the research and its aims were explained, she agreed to be interviewed in the researcher's room, but without audio recording.

Thus, holding the interview in a trusted environment was very important. In two countriesSpain and Georgia-they were held in the same building where victims previously had received support and services, while in Italy it was done in the privacy of the researcher's room.
The interview was designed to encourage/enable a relation of trust between the interviewer and the participant/survivor (Visentin et al. 2015).

When developing the guide, it was taken into consideration that these women had been through severe trauma and some must have lost trust in the system. Therefore, the interview began in an informal manner, speaking about the survivor's background, with the interviewers telling a bit about themselves, and gradually introducing the objectives and issues of the interview guide. In some cases, it was noticeable that questions about the victim's childhood help to gain trust. It was important to establish a positive rapport while explaining the flexible rules of the interview process, in order to create a pleasant atmosphere of trust, safety, and support, especially considering the sensitivity of dealing with this specific target population (Changa et al. 2005). All interviews took place in a comfortable environment, with the interviewers displaying empathy, warmth, and compassion towards the survivors (Changa et al. 2005; Campbell et al. 2009) and, in general, the conversation flowed naturally. The structure of the interview guide led the women gradually into their stories and allowed for different rhythms, considering each survivor's personal situation and background.

To illustrate this point, some women were ashamed of talking about their experience of being sexually abused and asked to switch off the voice recorder.

In a situation when a participant did not want to elaborate on some part of her experience and said,
"I don't want to talk more about it" (Georgia), the interviewer refrained from probing and went on to discuss another issue.

All women talked openly, were very emotional with moments of sorrow and tears, and then went back to their stories.

During an interview, one IDP in Georgia spoke about her traumatic experience of attempted suicide. Since the interviewer was a qualified psychiatrist, after completing the interview, she took time to discuss the participant's suicidal thoughts with her. Thus, holding the interview in an appropriate setting may allow for an intervention, when necessary. In contrast, the Romanian immigrant in Italy did not cry during the interview and there were only moments of silence. At times she talked about her own experience as if it was about another person. It seemed as if she was telling scenes from a movie that she was now watching again. During her interview, this survivor often mentioned the experiences of other immigrant women, also victims of intimate partners' violence.

In most cases, the interviews were part of the reflection or introspection process, which is often ongoing, considering the challenges that some women are still facing.

In addition, it was considered essential for the interview to have a proper closure, considering that for some participants, it was difficult to recall the past and talk about the violence experienced. Therefore, it was important to end the interview discussing the rehabilitation process, the wom- an's personal achievements, and her hopes for the future.

In general, the interview was a positive process for most of the women, which allowed them to reflect on all the years of abuse and suffering, the "breaking point" (the femicide attempt), and the changes after this event, including their rehabilitation process (although a few of them are still traumatized).

\section{Findings/Results}

This section encompasses three parts: the first relates to the issue of attempted femicide through shared characteristics of the survivors interviewed in different contexts and countries. The second part discusses important themes elucidated from the pilot study that should be especially addressed during the interview. Finally, some meaningful modifications and additions to the interview guide are discussed.

\section{Part 1: Common Characteristics in All Case Studies}

A common issue in all interviews was the extended suffering from severe violence. In the case of the survivors living in Spain and Italy, all women had a long history of beating and violence. Among the Georgian ones, five out of six women indicated that physical violence had started or was severe during their pregnancies, and the Chechen survivor said that physical violence occurred after the child was born. Three out of six Georgian women reported being sexually abused. 
In general, most survivors were ambivalent and expressed lack of trust towards professionals and security forces. This was more pronounced among women without legal status in the host country. The feeling of discrimination towards immigrants in the host country was an additional barrier to seeking help, as expressed clearly by the immigrants living in Spain. They were scared of complaining due to their perception that the authorities would always believe Spanish people (such as their husbands) over immigrant women, who were often treated as liars or as abusers of the system, and some had even been told: "You married for convenience" (to obtain benefits in the host country).

In the case of the Romanian survivor in Italy, this fear was compounded by the attitude of her Italian partner, who always reminded her that she is, "Only a Romanian immigrant and has no rights in Italy" and repeatedly indicated that all Romanians are criminals or prostitutes.

Most immigrant women also had had some negative experiences with doctors, policemen, and other professionals, and therefore did not have much faith in the people and in the systems of the host country. This was even more pronounced in the case of the Rumanian survivor in Spain because she was an illegal immigrant. Only one out of the six perpetrators in the Georgian cases was arrested. According to the survivor, her husband was only arrested because he also beat the policemen who arrived at the scene of violence. Otherwise, she believed that the police would not have arrested him, but would only have given him a warning, since they tend to see violence between partners as an internal family issue. Only one Georgian woman gave positive feedback about the police, explaining that she had never considered the possibility of separation until being informed about the availability of shelter by a police officer.

Similarly, the Romanian survivor in Italy appreciated the police (carabinieri) for doing their job and for the tips they had given her on how to avoid risky life situations. She also had positive perceptions of judges and lawyers, but not of social workers. This was explained by examples of immigrant women who lost custody of their children (because they were immigrants and did not have enough money). The Georgian participants had contacted health services at some point, but most did not consider them helpful.

A patriarchal culture of origin was common to most participants, as well as the fact that their husbands frequently got drunk, thus greatly increasing the level of domestic violence. All men were extremely jealous (control freaks) and wanted to exercise complete control over their partners, restricting the women's movement and activities. Half of the Georgian participants reported that their husbands were prescribed some psychotropic drugs by medical doctors. One partner was a criminal and presently lives in the Ukraine, because he is still wanted by police in Georgia.

Another common characteristic among some survivors was their social isolation, as in the case of the two Latin American women in Spain, who lacked their traditional family networks and support and for a long time did not find any alternative support in Spain. Thus, they were totally dependent on their spouses and did not share their situation with their families at home due to shame (as both came for middle/high socio-economic levels). This situation was also experienced by the Romanian survivor married to an Italian, although she secretly communicated with some family members.

Violence towards their children, either in the host country or in the country of origin, was also a common issue raised by many of the survivors. Among several of them, the children were involved and used as pawns by their husbands. The two women with Spanish husbands were scared of filing an official complaint, since in that case their children could be "taken from them." All the children were mistreated and they also witnessed the abuse and beating of their mothers for years.

In most of the Georgian cases, the children remained with their violent fathers, because they were considered more protected with them, since most women did not own their own home or property, due to cultural codes. This fact often influenced a woman's decision to stay with or even to go back to her husband after a separation period (since otherwise she could remain homeless and without money). In one instance, after the mother was thrown out of the family home, her daughter (who had stayed with her father) wrote an official letter refusing to meet her mother. According to the survivor, her daughter quit school in order to do all housework instead of her mother.
Part 2: Themes to Be Especially Addressed in Interviews

The pilot study validated most of the issues that composed the original draft interview guide. During its implementation, it was realized that better understanding of the key themes presented in this section was crucial for enabling a meaningful process through which the survivors could share their experiences.

\section{Living Inside Closed Communities with People from the Country of Origin}

If the survivor and her husband lived together in a closed community composed only of people from their country of origin, it is likely that the same values and behaviors will be reproduced, including those related to traditional and patriarchal gender roles. For example, the Romanian survivor interviewed in Spain shared the same apartment with people from her home town and there was a constant interaction among everyone. Nevertheless, not one of them intervened on her behalf when her husband beat her, since this was considered a normal behavior in their villages in Romania.

Violence may also increase in closed communities due to constant gossip, especially when a woman violates accepted gender behavioral expectations (for example, adopting modern dressing and lifestyle, going to bars, as well as talking or interacting with people-especially men-outside the closed community). 


\section{Survivors' Social Networks Considering} Their Partners Country of Origin

It is important to assess the survivor's social network and relationships in the host country. If a woman only socializes with family and friends from the community of origin, the values of that culture may be reproduced and even intensified, making a victim's violation of culturally accepted behavior even more punishable and her possibility to escape almost impossible, since there is strict social control over her. Therefore, the interview explored socio-cultural and symbolic meanings from the victims' countries and specific places of origin (such as villages or cities), as well as the level of patriarchal attitudes and practices. All these factors may influence the way in which the victim copes with the abusive situation in the host country.

The Georgian survivors were raised in an environment where the father was the head of the family, controlled everything, and women were relegated to a secondary status. They had to obey certain rules that were favorable to men. If a woman's parents said that they should marry a person, leave school, help in agricultural or housework, she had to do it. This patriarchal culture persists when they are living as IDPs.

Conversely, some Georgian husbands used their power (derived from their gender roles) to isolate their women from neighbors and community members, so that no one would intervene or prevent them from beating their wives.
Therefore, it is also crucial to explore the culture of both the survivor's and the aggressor's country of origin in order to understand the specific processes relating to violence.

\section{Perception of Threats and Resources \\ Available to the Victim/Survivor}

It was very important to understand the survivor's perception of the seriousness of the aggressor's threats, as well as her potential sources of support. This included both her personal support network (family, friends, workmate, etc.) and the formal system of support.

It was also crucial to assess the characteristics of the familial and informal support networks of the victim, identifying their presence, the strength of the relations, and how they would feel and react if the woman would opt for leaving the violent relationship. For example, Georgian survivors indicated that they were ashamed of sharing their problems with their families, and they knew that even if they would, their fathers and brothers' first reaction would be to tell her to be patient (and to continue living inside the violent situation). Therefore, some women preferred not to seek the support of their family.

A very important point to be considered was if a woman's social networks were really her own or were actually her partner's, which could have a negative impact on her overall situation, instead of providing her with the needed support. This was the case of the Colombian survivor in Spain, who emphasized that the aggressor's friends were her only social relations in the host country.

A woman's use of the official support system depends on her familiarity with the resources available to her and on her perception of their potential for helping her. Some survivors indicated the difficulties to access the host society's formal institutions, while others felt that these may even pose a threat to them.

This issue was addressed in the interview guide with questions such as: "How did you connect/ interact with the different services (police, health, social, legal, specific ones that deal with gender violence, female organizations, other)?" "How did they treat you/relate to you?"

At this point it was important to enquire about bureaucratic processes (both positive and negative experiences), as well as about their perception of culture and gender sensitivity of service providers.

\section{Barriers to Lodging Complaints}

One of the main objectives of our interview guide was to identify the barriers to filing official complaints to the police, the judicial system, or other institutions. This issue has been addressed in different sections of the interview. For example: "During the first period of the violent relationship, did you ask for help?" "When?" “Why?" "From whom (probe for a specific person, organization or institution, such as police, health or social services)?"
The barriers to lodge complaints or seek assistance identified during the pilot study included the feeling of shame for being in such a situation, the fear of the aggressor, the fear of the family's reaction, and of what the institutions could do as a result of a woman filing a complaint (for example, take away her child). An additional barrier was having an illegal status in the host country (due to fear of deportation), being scared of supporting and taking care of her children on her own ("When you have children, what can you do? You cannot divorce," Georgian survivor), as well as gender discrimination and other barriers related to cultural and symbolic meanings.

\section{Part 3: Important Changes and Additions to Original Draft Guide}

\section{Use of Violence by the Victims Themselves}

One issue that was not originally included among the interview guide's questions was the use of violence by the victims themselves, either self-inflicted or towards their partners, children, or other family members. This topic was raised during some interviews and thus relevant questions were added: "Have you ever tried to react to physical violence of your intimate partner?" “Why?" Or: “Why not?" "Could you recall if you have used violence towards your kids?" "When and why did it happen?"

\section{Specific Issues Related to the Perpetrators'} Behavior and Threats

Throughout the various phases of the interview, questions addressed the perpetrator's behavior 
and his history of violence towards the survivor. This issue was approached in different ways, depending on whether he was from the host country or from the same country of origin (and also if the relationship had begun there or if they had met in the host country). After the pilot study, it was decided to focus on some specific types of threats made by the aggressor. For example, when the Romanian survivor's husband was back in Romania (after having lived with her in Spain), his threats were a kind of blackmail affecting her reunification with her child (who at that point was also in Romania). Thus, he told her: "If you want the boy to return to Spain, I must sign [an authorization for him to leave Romania], otherwise he can't go." Of course, different conditions were attached to this signature.

Therefore, in cases when there are children involved, specific questions were added, such as: "What threats have you received from your partner?" "Were any of them related to your child?" "Has he tried to blackmail you?" "How?" "What did you do?"

These kinds of threats also occurred when the immigrant woman's partner was a citizen of the host country. In that case, the threat often focused on her inferior position as an immigrant. To illustrate this point, the Spanish partner of the Mexican survivor in Spain put a lot of pressure on her, emphasizing his nationality and therefore his superior rights: "I am Spanish, you are only a foreigner and [therefore] you are the one who will be blamed" or "Who will believe you?" (from field notes).
Thus, it was decided to add some questions to the interview guide to enable a better identification of aggressors' specific types of behaviors and threats. Mixed couples (usually an immigrant woman and a local man) should be especially address targeted questions, since the man can easily take advantage of this point.

\section{Focusing on the Children's Experiences}

As a consequence of our pilot interviews with immigrant survivors of attempted femicide, in which a child played an important role in the process which ultimately lead to the femicide attempt in all cases, we realized that their overall situation should be better explored. Therefore, a few questions regarding a woman's violence towards her children were added mostly relating to her life in the host country and specifically to the changes in the relationship with the partner and increased violence.

In the original guide, in case the survivor had children, she was asked: "How did this situation [of violence] affect them?" "Were they abused?" "Were they in danger?"

In the revised guide, the following questions were added: "As a consequence of all the aforesaid, did you ever display violence towards your children?" "Please explain in what ways, in which occasions, and what were the triggers that lead to this."

In the improved version of the interview guide, the gender issue related to the child was incorpo- rated into these questions, since it had not been expanded in the original guide (instructions: please enquire both for boys and for girls).

\section{Adaptations Related to the Different Types of Interview Populations}

Originally, the interview guide was developed to target immigrant women who survived attempted femicide in European host countries. Throughout the pilot study we realized that there were other specific populations for which this tool could be relevant and useful. The first are the internally displaced people (IDPs) who were forced to leave their areas of origin (for example, due to political turmoil or foreign occupation, like in Georgia). Considering that IDPs are from the same country of origin (but from another area of the country and often belonging to an ethnic minority group), the terminology: "host country" and "home country" must be adapted throughout the interview guide, as well as other questions related to the place of origin. In addition, the causes that led to this internal displacement should be further investigated. For example, the women interviewed in Georgia were mostly IDPs, meaning that the country was the same, but the locations were different, since many of the people's "hometowns" are still occupied by foreign forces. Thus, some changes were made in the text, using terms such as "before displacement" and "after displacement."

For example, instead of asking: “Why did you decide to immigrate and come to [host country]?" "Please tell us about the immigration process it- self since you left your hometown till arrival in this country" "Please explain the difficulties you had," IDPs were asked: "Why did you decide to move?" "How did you make this decision?" "Please tell us about the displacement process itself since you left your home till arrival in this place" "Please explain the difficulties you had."

Other populations with similar characteristics could benefit from this interview tool in the future, such as second or third generation immigrants who live in closed communities (ghettos) in big cities across Europe. A final target population could be women victims of violence among the hundreds of thousands of asylum seekers and refugees who arrived in Europe in the last few years (Freeman 2016), having gone through long and traumatic journeys (from Middle Eastern countries at war and from Africa). This may be an important population to focus on in the future, especially since violence and the risk of femicide may escalate under these circumstances.

\section{Conclusions}

The aim of this paper was to present the ongoing development process of a culture-sensitive interview guide which could be used for female victims of violence and survivors of attempted femicide who are immigrants, have been displaced, and are living away from their familiar/ home environment. It was based on previous initiatives (Nicolaidis et al. 2003) and the issues to be addressed in the guide were identified from a review of the relevant literature. As indicated, it was found that in general there is a higher 
prevalence of violence among people with a migrant background (European Union Agency for Fundamental Rights 2014). Therefore, the objective of the guide is to enable an in-depth assessment of the dynamics and mechanisms related to this specific type of violence, thus making it relevant to violence prevention and femicide, as well as for public policies on these issues in the European context.

When developing this pilot study, immigrant women living in European host countries were targeted (such as the cases in Spain and Italy), as well as women displaced inside their own country (Georgia). In the future, female refugees who are in host countries or still in temporary settlements should also be addressed.

Similar issues and circumstances were shared by women in both scenarios (immigrants and IDPs). These included the presence of an entrenched patriarchal culture, certain characteristics of the aggressors (such as alcohol or substance abuse), and long histories of violence or use of certain strategies to pressure the woman, including the manipulation of their relationship with their children. In addition, certain changes experienced by an immigrant woman in the host country often increased the risk of violence (for example, a decrease in her socio-economic status which increased her dependency on her partner, or xenophobic attitudes and exclusion due to her skin color). Thus, it may be useful to consider the intersectionality approach as a more comprehensive way to analyze the issues identified (Sokoloff and Dupont 2005).
In future studies, it will be important to further discuss the situation of survivors that are married to men from other countries and of women with children. In the case of women married to men from host countries, it may be necessary to include additional questions related to the victim's relationship with other community members (neighbors, colleagues, other immigrants), as well as to the threats received from their partners.

After piloting this interview guide in the field, some methodological reflections regarding its use and application were considered. First of all, it is essential to create an atmosphere of trust that takes into account both the survivor's place in the context of the host country (her general situation, level of integration, characteristics of violent relationship, etc.), as well as relevant specific cultural aspects from her country of origin. Secondly, it is important to consult with professionals (such as caseworkers) in order to identify if a survivor is at a stage in her rehabilitation process in which she is ready to participate in this kind of interview. In addition, it was found that the structure of the interview guide helped women to focus and to be able to share important parts of their stories, since in a few cases, the beginning of the narratives had been fragmented with participants jumping from one topic to another, making it hard to follow the story.

Considering the aforesaid, the interviewers using this guide should be experienced with qualitative research in very delicate situations (Changa et al. 2005; Campbell et al. 2009). Some studies indicate important elements and strategies to be used among victims of violence, such as acceptance and empathy, establishing a bond of trust between the professional and the woman, including dialogue, and intent listening. These issues should be addressed in the training of professionals (Visentin et al. 2015).

Another important aspect of the interview guide is its flexibility, both in the form and in the order of the questions and issues raised, as well as in the option to dwell on specific cultural issues that may arise during the interview. As previously explained, it is essential for the interviewer to understand the survivor's background and cultural codes, in order to enable the elaboration of details that may be critical to fully understanding her situation. For example, one of the Georgian interview narratives involved a sex-selective abortion. A survivor's husband had told her that if she gave birth to a son, everything would be fine. But, since she had a girl, she was forced to have an abortion. This is related to some patriarchal cultural codes, in which sons have a higher value than girls and nowadays, as a result of ultrasound technology, selected abortions of female fetuses occur. Therefore, questions should also be adapted to culture-specific issues.

Finally, when applying the interview guide, it is essential to be aware of the survivor's stage in the rehabilitation process. It was considered important to interview women who were in an advanced stage of their rehabilitation process (especially regarding coping with their traumatic experiences). If a newly arrived woman to a shelter is interviewed, who has just begun her treatment, she may be overwhelmed by the exposure of the trauma, which may also affect the interview. This was confirmed in one of the case studies, in which the discussion evoked suicidal thoughts. Since one of the interviewers was a psychiatrist, she was able to deal with the situation, which could have been prevented during the selection process. Thus, when piloting this guide in different countries and cultural contexts, it is recommended to discuss and to coordinate the selection of potential femicide survivors to be interviewed with their caseworkers or professionals, in order to determine if they are able to participate in this kind of interview.

Upon completion of the development of the interview guide, it is recommended to conduct an additional pilot among a few more survivors of failed femicide ${ }^{5}$ in order to finalize this ongoing process leading to a standardized interview guide, which can be adapted to local socio-cultural contexts, enabling comparative studies across Europe.

\section{Acknowledgement}

This ongoing project was made possible due to the support of COST Action 1206, which granted STSM (short-term scientific missions) to Nudelman, Boira, and Balica, thus enabling the field work and the development of the qualitative tool presented in this paper.

5 Professionals who are interested in collaborating in the validation process are requested to contact the first 


\section{References}

Abu Rabia, Aref. 2011. "Family Honor Killings: Between Custom and State Law." The Open Psychology Journal 4:34-44.

Balica, Ecaterina. 2016. Homicide-Suicide in Romania: Statistical Data and Media Representation. Belgium: Peter Lang Publishing House.

Balica, Ecaterina and Heidi Stöckl. 2016. “Homicide-Suicides in Romania and the Role of Migration." European Journal of Criminology 13(4):517-534.

Boira, Santiago. 2010. Hombres maltratadores. Historias de violencia masculina. Zaragoza: Prensas Universitarias de Zaragoza.

Boira, Santiago and Pedro Jodrá. 2010. “Psicopatología, características de la violencia y abandonos en programas para hombres violentos con la pareja: resultados en un dispositivo de intervención." Psicothema 22:593-599.

Boira, Santiago and Chaime Marcuello. 2013. “Male Abuser: Type of Violence and Perception of the Relationship with the Victim." Psychological Reports 112:210-238.

Boira, Santiago et al. 2013. "Context of Treatment and Therapeutic Alliance: Critical Factors in the Intervention with Court-Ordered Batterers." The Spanish Journal of Psychology 16(40):1-13.

Briones-Vozmediano et al. 2014. “Professionals' Perceptions of Support Resources for Battered Immigrant Women: Chronicle of an Anticipated Failure." Journal of Interpersonal Violence 29(6):1006-1027.

Campbell, Rebecca et al. 2009. “Training Interviewers for Research on Sexual Violence: A Qualitative Study of Rape Survivors' Recommendations for Interview Practice." Violence against Women 15(5):595-617

Carbajosa, Pablo et al. 2011. El delito de violencia de género y los penados extranjeros. Madrid: Secretaría General Técnica del Ministerio del Interior.

Changa, Judy C. et al. 2005. “Asking about Intimate Partner Violence: Advice from Female Survivors to Health Care Providers." Patient Education and Counseling 59:141-147.
Chikovani, Ivdity et al. 2015. "Health Service Utilization for Mental, Behavioural and Emotional Problems among Conflict-Affected Population in Georgia: A Cross-Sectiona Study." Plos One 10(4). Retrieved June 17, 2017 (http://journals. plos.org/plosone/article?id=10.1371/journal.pone.0122673).

Consejo General del Poder Judicial. 2015. Datos de denuncias, procedimientos penales y civiles registrados, Órdenes de protección y medidas de protección y seguridad solicitadas En los juzgados de violencia sobre la mujer (JVM) y sentencias dictadas Por los órganos jurisdiccionales en esta materia en el año 2015. Madrid: Consejo General el Poder Judicial. Retrieved July 01, 2016 (www. poderjudicial.es/cgpj/es/Poder_Judicial).

Davis, Robert C., Edna Erez, and Nancy Avitabile. 2001. “Access to Justice for Immigrants Victimized by Crime: The Perspectives of Police and Prosecutors." Criminal Justice Policy Review 12(3):183-196.

Edelstein, Arnon. 2013. "Culture Transition, Acculturation and Intimate Partner Homicide." SpringerPlus 2:338.

European Union Agency for Fundamental Rights. 2014. Violence against Women: An EU-Wide Survey. Luxembourg: Publications Office of the European Union.

Freeman, Jane. 2016. “Sexual and Gender-Based Violence agains Refugee Women: A Hidden Aspect of the Refugee Crisis." Re productive Health Matters. Retrieved July 30, 2016 (http://www. sciencedirect.com/science/article/pii/S0968808016300118).

Gonzalez-Mendez, Rosaura and Juana D. Santana-Hernandez. 2012. "Professional Opinions on Violence against Women and Femicide in Spain." Homicide Studies 16(1):41-59.

Gracia, Enrique et al. 2010. "Percepciones y actitudes hacia la violencia de pareja contra la mujer en inmigrantes Latinoamericanos en España." Intervención Psicosocial 19(2): 135-144.

Hazen, Andrea L. and Fernando I. Soriano. 2007. “Experiences with Intimate Partner Violence among Latina Women." Vi olence against Women 13:562-582.
Herrera, Sonia. 2013. Trapped in the Limbo. Women, Migration and Sexual Violence. Barcelona: Cristianismo y Justicia.

IDMC. 2014. Georgia IDP Figures Analysis. Retrieved July 05, 2016 (http://www.internal-displacement.org/europe-the-caucasus-and-central-asia/georgia/figures-analysis).

Ingram, Eben M. 2007. “A Comparison of Help Seeking between Latino and Non-Latino Victims of Intimate Partner Violence." Violence against Women 13(2):159-171.

Instituto de la Mujer y para la Igualdad de Oportunidades. Ministerio de Sanidad, Servicios Sociales e Igualdad. Gobierno de España. Retrieved July 01, 2015 (http://www.inmujer.gob.es/ estadisticas/consulta.do?metodo=buscar).

Israeli Parliament, Research and Information Center. 2015. Data on Violence against Women for 2015. Report presented to theCommittee for Advancement of Women's Status.

Laurent, Claire, Michael Platzer, and Maria Idomir. 2013. Femicide: A Global Issue That Demands Action. Vienna: Academic Council on the United Nations System (ACUNS) Vienna Liaison Office.

Makhashvili, Nino et al. 2014. “Mental Disorders and Their Association with Disability among Internally Displaced Persons and Returnees in Georgia." Journal of Traumatic Stress 27(5):509-518.

McNamara, Patricia. 2008. “Changed Forever: Friends Reflect on the Impact of a Woman's Death through Intimate Partner Homicide." Journal of Family Studies 14:198-216.

Messing, Jill T. et al. 2013. “Culturally Competent Intimate Partner Violence Risk Assessment: Adapting the Danger Assessment for Immigrant Women." Social Work Research 37(3):263-275.

Ministerio de Sanidad, Servicios Sociales e Igualdad. 2015. Macroencuesta de violencia contra la mujer 2015. Madrid: Gobierno de España.

Nicolaidis, Christina et al. 2003. "Could We Have Known? A Qualitative Analysis of Data from Women Who Survived an
Attempted Homicide by an Intimate Partner." Journal of General Internal Medicine 18:788-779.

Nudelman, Anita. 2013. Gender-Related Barriers to Services for Preventing New HIV Infections among Children and Keeping Their Mothers Alive in High-Burden Countries. UNAIDS: Discussion Paper. Retrieved June 17, 2017 (www.unaids.org/en/media/unaids/contentassets/documents/unaidspublication/2013/201312 discussion-paper_Gender-HIV-services_PMTCT_en.pdf).

Prosecutor's Office of Georgia. 2015. Retrieved July 03, 2016 (pog gov.ge/res/docs/holideiinn/qaltamkvlelobebiojaxurinishnit.pdf).

Raj, Anita and Jay Silverman. 2002. "Violence against Immigrant Women: The Roles of Culture, Context, and Legal Immigrant Status on Intimate Partner Violence." Violence agains Women 8:367-398.

Rana, Sheetal. 2012. Addressing Domestic Violence in Immigrant Communities: Critical Issues for Culturally Competent Services. Harrisburg, PA: VAWnet, a project of the National Resource Center on Domestic Violence.

Ross, John. 2012. Reproductive Health Survey Georgia 2010: Final Report. Retrieved June 17, 2017 (http://en.calameo.com/ books/000713529a8d3173e7e0a).

Runner, Michael, Mieko Yoshihama, and Steve Novick. 2009. Intimate Partner Violence in Immigrant and Refugee Communities: Challenges, Promising Practices and Recommendations. Princeton, NJ Robert Wood Johnson Foundation and Futures without Violence.

Sanz-Barbero, Belén et al. 2016. “Perfil sociodemográfico del feminicidio en España y su relación con las denuncias por violencia de pareja." Gaceta Sanitaria 30(4):272-278.

Sela-Shayovitz, Revital. 2010. “The Role of Ethnicity and Context: Intimate Femicide Rates among Social Groups in Israeli Society." Violence against Women 16:14-24.

Shalhoub-Kevorkian, Nadera. 2003. "Reexamining Femicide Breaking the Silence and Crossing 'Scientific' Borders." Signs: Journal of Women in Culture and Society 28(2):581-608. 
Sheehan, Brynn E. et al. 2015. "Intimate Partner Homicide: New Insights for Understanding Lethality and Risks." Violence against Women 21(2):269-288.

Sokoloff, Natalie J. and Ida Dupont. 2005. “Domestic Violence at the Intersections of Race, Class, and Gender. Challenges and Contributions to Understanding Violence against Marginalized Women in Diverse Communities." Violence against Women 11:38-64.

Visentin, Fernanda et al. 2015. “Women's Primary Care Nursing in Situations of Gender Violence." Investigacion y Educacion en Enfermeria_33(2):556-564.
Weil, Shalva. 2015. "Combating Femicide in Multiple Ways: The COST Action 1206 on 'Femicide Across Europe."' Femicide III. Vienna: ACUNS-Academic Council of the United Nation System. Retrieved July 15, 2016 (http://acuns.org/wp-content/ uploads/2015/04/Femicide-III_Core-Stanzell.pdf).

Weil, Shalva. 2016. “Making Femicide Visible." Current Sociology 64(7):1124-1137.

WHO. 2009. Children of Georgia. An Assessment of the Mental Health and Psychosocial Support Needs of the Conflict-Affected Populations. Tblisi, Georgia: WHO. 